\section{Futebol e política: transculturação e transformação no mundo da língua portuguesa}

O futebol é um jogo do espaço e de espaços, que possibilita associar a sua cultura, história e dimensão política com a espacialidade inscrita na constituição do mundo da língua portuguesa e cuja concretude no próprio jogo ascende ao plano metafórico ("a profundidade do espaço", "estreitar espaços", "ocupar espaços" etc.). A partir desse ponto de vista evidenciamse de maneira patente os significados simbólicos e discursivos, que partem dos relvados e são projetados ou assimilados pela sociedade. Isso começa com o estádio enquanto espaço de encontro e de segregação, atende às possibilidades complexas do espaço midiático e, hoje em dia, conduz quase que imediatamente ao espaço virtual.

O futebol, por sua relevância social e por sua carga simbólica, pode ser ele próprio um lugar de memória ou produzir tais lugares de memória, ele é o campo de disputa para utopias e distopias, atravessa ou estabiliza fronteiras com sua significativa atuação, dependendo de como é politicamente empregado, usado e até mesmo manipulado. Por exemplo, o Estádio do Maracanã, "templo de futebol" localizado no Rio de Janeiro, em sua forma original era o símbolo de uma visão democrática de espaço, porém, tornou-se o lugar da memória traumática da nação brasileira na Copa de 1950 e, através da reforma para a Copa de 2014, converteu-se em símbolo da comercialização e da exclusão de amplos segmentos da população.

O lendário Eusébio (1942-2014) foi um exemplo ideal do jogador modelo do regime colonial salazarista, mas, ao mesmo tempo, foi também propulsor da valorização e da elevação de autoestima das colônias portuguesas em África. Além disso, alguns nomes importantes nos movimentos de independência africanos, como o do político de Guiné-Bissau, Amilcar Cabral (1924-1973), mantinham laços estreitos com o meio futebolístico em seus países de origem. ${ }^{1}$

${ }^{1}$ Importantes contribuições para essa temática são as obras Mais do que um jogo - o esporte e o continente africano (Nascimento et al., 
A transculturação em si já significa transformação dos atores e de forças envolvidas e, ao mesmo tempo, representa uma das forças mais poderosas de mudança social. Nesse sentido, o futebol no mundo de língua portuguesa é um excelente exemplo dos mais diversos e variados processos de transculturação no passado e no presente. 0 jogo com a bola de couro era uma atividade de lazer das elites coloniais ou neocoloniais e, ao mesmo tempo, uma forma de autoafirmação e de libertação de povos e grupos populacionais oprimidos, marginalizados e discriminados. 0 futebol tornou-se instrumento de luta a favor e contra as demarcações sociais e, sobretudo, étnicas, bem como meio de afirmação de construções identitárias "híbridas". No Brasil, em Portugal e nos países africanos de língua portuguesa, o futebol é um elemento

Rio de Janeiro, Apicuri, 2010) e Esporte e lazer na África: novos olhares (Melo et al., Rio de Janeiro, 7Letras, 2013), bem como os livros Futebol e colonialismo: corpo e cultura popular em Moçambique, de Nuno Domingos (Lisboa, Imprensa de Ciências Sociais, 2012), e A bola ao ritmo de fado e samba - 100 anos de relações luso-brasileiras no futebol (Porto, Edições Afrontamento, 2013), publicação organizada por Francisco Pinheiro e Victor Andrade de Melo. central da cultura popular há décadas e tem uma capacidade elevada de evocar o sentimento de identidade.

Os ensaios reunidos no Dossiê da presente edição - com exceção do texto de Wilder Kleber Fernandes de Santana e Rafael Marques Garcia - se originaram de comunicações e palestras apresentadas na secção "Futebol e política - transculturação e transformação no mundo da língua portuguesa", no âmbito do XIII

\section{Congresso Alemão de Lusitanistas: espaços, fronteiras} e passagens no mundo de língua portuguesa, realizado na Universidade de Augsburg, Alemanha, em setembro de 2019. No seu conjunto, esses estudos examinam a densidade e complexidade do futebol esboçadas acima, que o torna um motor, um meio e também um objeto de transculturação e de transformação. ${ }^{2}$

O dossiê se inicia com o ensaio de Francisco Pinheiro, “O 'lápis azul' no sport português - política,

\footnotetext{
${ }^{2}$ Gostaríamos de agradecer de coração a todos os participantes da mencionada seção pelas discussões animadas, profundas e enriquecedoras, também àqueles que, por razões diversas, infelizmente, não puderam propor textos elaborados a partir de suas valiosas falas.
} 
desporto e media”, que analisa as dinâmicas da censura e do denominado "lápis azul" nos principais jornais esportivos portugueses (A Bola, Mundo Desportivo, $O$ Norte Desportivo, Record) durante o regime salazarista, fazendo uma ampla reflexão sobre a relação entre política e esporte no contexto do fascismo português. 0 texto apresenta as ocorrências mais relevantes, as tipologias de punições por parte dos serviços de censura e as formas de controle e coação da imprensa esportiva adotadas pelo regime.

Em seu texto "O processo de transformação do futebol como elemento da identidade nacional brasileira", Guilherme Silva Pires de Freitas e Luiz Gonzaga Gogoi Trigo analisam o processo de transformação do futebol como elemento da identidade nacional brasileira na primeira metade do século $\mathrm{XX}$, consolidando-se principalmente entre as décadas de 1930 e 1950 . Neste período o futebol brasileiro foi utilizado como instrumento político durante o Estado Novo, causando forte comoção nacional após a derrota para o Uruguai na Copa do Mundo de 1950 e atingindo a sua consagração com o título mundial em
1958, momento em que os brasileiros assumiram de vez esta prática esportiva como parte de sua identidade nacional, fortalecendo ainda mais a expressão que o Brasil era o "país do futebol".

Em sua contribuição "Corpos subversivos: um olhar sobre o futebol na poesia de João Cabral", Rodrigo Garcia Barbosa busca identificar as dimensões artística, ideológica e afetiva através das quais o futebol é apreendido pela poesia de João Cabral de Melo Neto, com especial atenção para a dimensão ideológica e seus desdobramentos políticos, a partir da leitura do poema “Brasil 4 x Argentina 0" (1981) sobre uma partida entre essas duas seleções.

Ainda no campo da literatura brasileira, em "Futebol em campo minado: representações da violência e da morte em 'Cemitério clandestino', de Ana Paula Maia, e 'Ademir', de Mayrant Gallo", Tânia SarmentoPantoja analisa os dois contos mencionados. "Ademir" pertence à coletânea de contos de Mayrant Gallo - todos dedicados ao futebol - intitulada 0 gol esquecido: contos de futebol (2014), enquanto "Cemitério clandestino" 
pode ser encontrado em Entre as quatro linhas: contos sobre futebol (2013), coletânea organizada por Luiz Ruffato, que reúne quinze contistas. Dois aspectos, presentes em ambos os contos, movimentam a análise: 0 futebol e a violência.

Em "Mais branco do que preto na ditadura militar brasileira: a Democracia Corinthiana, sindicalismo, a rebeldia e o rock and roll", Augusto Sarmento-Pantoja nos conduz à área do audiovisual, para discutir o documentário Democracia em preto e branco (2014), de Pedro Asbeg, e suas relações entre política, futebol e música. 0 documentário, comemorativo dos 30 anos do fim do movimento "Democracia Corinthiana” (1982-84), possibilita reconstruir como esse movimento saiu dos campos de futebol e se transformou em ponte política para engrossar a massa de protestos a favor da democracia e pelas eleições diretas para presidente da república no Brasil. A partir dali, Augusto SarmentoPantoja busca discutir as estratégias de resistência e autoritarismo para que o movimento, tanto da democracia quanto das diretas, se tornasse mais branco do que preto.
Em “O João sem medo e as onze feras: Warum und wie der Journalist und bekennende Kommunist João Saldanha 1969 Trainer der Seleção wurde", Sebastian Knoth nos faz voltar um pouco na história recente do futebol brasileiro e analisa a carreira do jornalista e técnico de futebol João Saldanha (1917-1990), assim como as circunstâncias sócio-históricas no final dos anos 1960 no Brasil, período em que Saldanha foi convocado para assumir o comando da seleção brasileira. As dinâmicas e os conflitos em volta da convocação e demissão de Saldanha como técnico da seleção brasileira, durante um dos momentos de maior repressão imposta pelo regime civil militar, foram fatores políticos importantes naquele momento e ultrapassaram em muito os limites do mundo do futebol.

A perspectiva sócio histórica continua e se intensifica na contribuição "O futebol contemporâneo brasileiro e a constituição de sujeitos trans: sob as lentes do cronotopo bakhtiniano", de Wilder Kleber Fernandes de Santana e Rafael Marques Garcia, que analisa a constituição de sujeitos trans no futebol contemporâneo brasileiro - 
"modalidade esportiva consagrada como templo de reserva masculina" - sob a ótica do termo bakhtiniano de cronotopo, e traça processos de (des)naturalização das concepções de sujeito no tempo e no espaço.

Por sua vez, Marcel Vejmelka analisa em seu ensaio a tríade de "Política, futebol e mito em miniatura: Fealdade de Fabiano Gorila, de Marcello Quintanilha", uma espécie de "conto gráfico" de 1999 que combina a trajetória individual de um jogador de futebol com a evolução histórica do jogo em meados dos anos 1950 e com o destino político do Brasil. Combinando a arte visual em geral com as técnicas específicas das histórias em quadrinhos e com a dimensão narrativa tradicional, Quintanilha cria uma miniatura dentro da qual é possível identificar alguns momentos de mudança dentro do jogo que permitem analisar a evolução político-social do Brasil, e vice-versa, momentos de transformação política que vão repercutir no futebol.

Por fim, o dossiê se encerra com uma proposta teórica inusitada e inspiradora de Mauricio Mendonça Cardozo, quem em "Tradução, futebol e o flagrante da relação" parte do pressuposto de que o futebol e a tradução, apesar de seu pertencimento a esferas tão distintas da cultura e da sociedade, são dois fenômenos culturais de grande impacto, relevância e abrangência. A partir dali, experimenta diferentes possibilidades de aproximação entre os domínios da tradução e do futebol, demonstrando como esses dois universos, apesar de aparentemente tão incomensuráveis, têm mais coisas em comum do se poderia suspeitar, e identifica perspectivas de aproximação que nos permitam tomar por base algumas das experiências do domínio da tradução para enxergar, com outros olhos, algumas das questões do mundo do futebol, e vice-versa, com destaque para a questão da relacionalidade.

A seção Paralelas inclui o ensaio de Fausto Amaro Ribeiro Picoreli Montanha, "As mulheres nos esportes olímpicos: olhares da imprensa carioca (19201935)", no qual o autor investiga as narrativas da imprensa carioca sobre a participação feminina nos esportes olímpicos entre os anos de 1920 e 1935. Com base na análise de jornais e revistas cariocas desse 
período, Fausto Amaro situa a representação do feminino e a postura dos jornalistas e de outros atores diante de uma presença cada vez maior de mulheres na esfera do esporte e verifica que a abordagem temática no esporte (graça, beleza, maternidade) não diferia do que era esperado socialmente da mulher à época, e que jornalistas e dirigentes esportivos se opunham explicitamente aos avanços femininos no esporte, lançando mão de argumentos pseudocientíficos baseados na tradição para justificar seus posicionamentos.

A seção Poética é composta por três poemas, em que Kaio Carmona associa futebol e erotismo (ludo e eros). Os versos do pesquisador e poeta belo-horizontino nos evocam outro mestre da língua portuguesa, o escritor gaúcho Luis Fernando Veríssimo, que não associa futebol e erotismo, mas sim futebol e sexo em uma de suas famosas crônicas:

No futebol, como no sexo, tem gente que se benze antes de entrar e sempre sai ofegante.
No sexo, como no futebol, tem o feijão com arroz, mas também tem o requintado, a firula e o lance de feito. E, claro, o lençol.

No sexo também tem gente que vai direito no calcanhar.

E tanto no sexo quanto no futebol o som que mais se ouve é aquele "uuu".

No fim, sexo e futebol só são diferentes, mesmo, em duas coisas. No futebol, não pode usar as mãos. E o sexo, graças a Deus, não é organizado pela $\mathrm{CBF}{ }^{3}$

Desejamos a todos uma boa leitura!

Elcio Loureiro Cornelsen Universidade Federal de Minas Gerais/Brasil

Marcel Vejmelka Universidade de Mainz/Alemanha

Belo Horizonte e Germersheim, 12 de fevereiro de 2020.

${ }^{3}$ VERÍSSIMO. Sexo e futebol. Time dos sonhos: paixão, poesia e futebol. São Paulo: Objetiva, 2010, p. 119-120. 